This item was submitted to Loughborough's Research Repository by the author.

Items in Figshare are protected by copyright, with all rights reserved, unless otherwise indicated.

\title{
New insights into electrocatalytic ozone generation via splitting of water over PbO2 electrode: A DFT study
}

PLEASE CITE THE PUBLISHED VERSION

http://dx.doi.org/10.1016/j.cplett.2016.04.078

\section{PUBLISHER}

(C) Elsevier

VERSION

AM (Accepted Manuscript)

\section{PUBLISHER STATEMENT}

This work is made available according to the conditions of the Creative Commons Attribution-NonCommercialNoDerivatives 4.0 International (CC BY-NC-ND 4.0) licence. Full details of this licence are available at: https://creativecommons.org/licenses/by-nc-nd/4.0/

\section{LICENCE}

CC BY-NC-ND 4.0

\section{REPOSITORY RECORD}

Gibson, Gregory, Ashley Morgan, Peijun Hu, and Wen-Feng Lin. 2016. "New Insights into Electrocatalytic Ozone Generation via Splitting of Water over Pbo2 Electrode: A DFT Study". figshare. https://hdl.handle.net/2134/21375. 


\section{Accepted Manuscript}

New insights into electrocatalytic ozone generation via splitting of water over

$\mathrm{PbO}_{2}$ electrode: A DFT study

Gregory Gibson, Ashley Morgan, P. Hu, Wen-Feng Lin

PII:

S0009-2614(16)30263-9

DOI:

http://dx.doi.org/10.1016/j.cplett.2016.04.078

Reference:

CPLETT 33822

To appear in:

Chemical Physics Letters

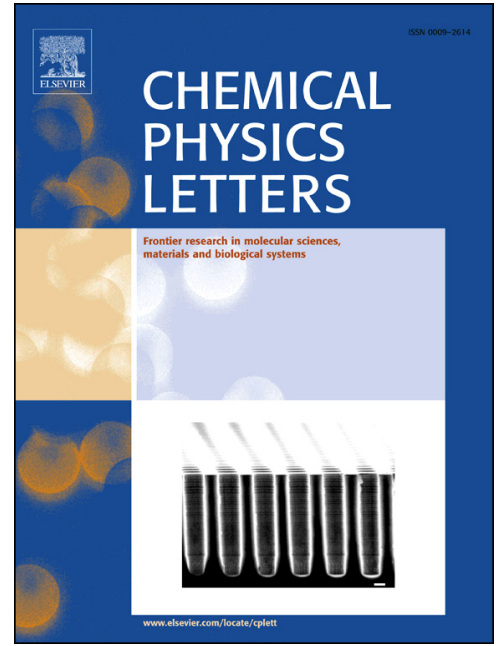

Received Date:

14 January 2016

Accepted Date:

21 April 2016

Please cite this article as: G. Gibson, A. Morgan, P. Hu, W-F. Lin, New insights into electrocatalytic ozone generation via splitting of water over $\mathrm{PbO}_{2}$ electrode: A DFT study, Chemical Physics Letters (2016), doi: http://dx.doi.org/ 10.1016/j.cplett.2016.04.078

This is a PDF file of an unedited manuscript that has been accepted for publication. As a service to our customers we are providing this early version of the manuscript. The manuscript will undergo copyediting, typesetting, and review of the resulting proof before it is published in its final form. Please note that during the production process errors may be discovered which could affect the content, and all legal disclaimers that apply to the journal pertain. 


\title{
New insights into electrocatalytic ozone generation via splitting of water over $\mathrm{PbO}_{2}$ electrode: A DFT study
}

Gregory Gibson ${ }^{\mathrm{a}, \mathrm{b}}$, Ashley Morgan ${ }^{\mathrm{b}}, \mathrm{P} . \mathrm{Hu}^{\mathrm{b}}$ and Wen-Feng Lin ${ }^{\mathrm{a}, \mathrm{b}^{*}}$

${ }^{a}$ Department of Chemical Engineering, Loughborough University, Loughborough, Leicestershire, LE11 3TU, UK.

${ }^{b}$ Centre for the Theory and Application of Catalysis, School of Chemistry and Chemical Engineering, Queen's University of Belfast, Belfast BT9 5AG, U.K.

\begin{abstract}
The viable mechanisms for $\mathrm{O}_{3}$ generation via the electrocatalytic splitting of $\mathrm{H}_{2} \mathrm{O}$ over $\beta$ $\mathrm{PbO}_{2}$ catalyst were identified through Density Functional Theory calculations. $\mathrm{H}_{2} \mathrm{O}$ adsorbed onto the surface was oxidized to form $\mathrm{OH}$ then $\mathrm{O}$; the latter reacted with a surface bridging $\mathrm{O}$ to form $\mathrm{O}_{2}$ which in turn reacted with another surface $\mathrm{O}$ to form $\mathrm{O}_{3}$. The final step of the mechanisms occurs via an Eley-Rideal style interaction where surface $\mathrm{O}_{2}$ desorbs and then attacks the surface bridging oxygen, forming $\mathrm{O}_{3}$. A different reaction pathway via an $\mathrm{O}_{3} \mathrm{H}$ intermediate was found less favoured both thermodynamically and kinetically.
\end{abstract}

Keywords: Electrochemical Ozone Production, Density Functional Theory, Advanced Oxidation Technology, Lead Oxide, Activation Energy, Reaction Pathway

*Corresponding author at Loughborough University: E-mail: w.lin@ lboro.ac.uk (W. F. Lin). 


\section{Introduction}

Ozone $\left(\mathrm{O}_{3}\right)$ is a strong oxidant with wide applications across many disciplines related to advanced oxidation technologies. Due to its strong oxidizing nature $\mathrm{O}_{3}$ is often used in disinfection processes at wastewater treatment facilities. It has relevance in removing unwanted odours, wood pulp bleaching and more recently in healthcare [1-6]. For practical uses, $\mathrm{O}_{3}$ must be produced in an efficient and environmentally friendly manner, which to date has proven to be the greatest challenge. At present $\mathrm{O}_{3}$ is produced industrially via the Cold Corona Discharge (CCD) method. This process involves two electrodes with alternating current, similar to an electric spark, with pure oxygen $\left(\mathrm{O}_{2}\right)$ or dry air passing between them. Current efficiency (CE) values tend to be low at between 2-12 wt\% depending on the source of $\mathrm{O}_{2}[7,8]$.

Through the use of electrochemistry and in particular, electrocatalysis, a superior $\mathrm{O}_{3}$ yield can be achieved via water splitting. In electrolysis, $\mathrm{H}_{2} \mathrm{O}$ undergoes decomposition at the anode through either a 4 or 6 electron process shown in reactions 1 and 2 [9]:

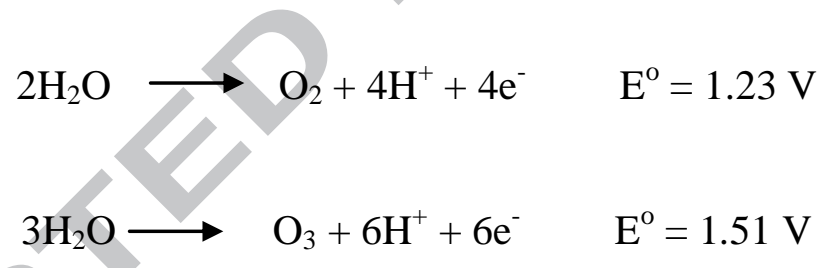

Reaction (1) shows the competing reaction, the formation of $\mathrm{O}_{2}$ that can occur instead of the formation of $\mathrm{O}_{3}$ in reaction (2). This can be quantified using thermodynamics. In comparison to $\mathrm{O}_{3}, \mathrm{O}_{2}$ is thermodynamically superior in terms of stability and thus will readily form. To combat this, the inhibition of $\mathrm{O}_{2}$, and hence the formation of $\mathrm{O}_{3}$ is of paramount importance. By running at a high onset potential with a large applied overpotential the thermodynamic barrier can be bypassed, resulting in $\mathrm{O}_{3}$ formation. In selecting a suitable catalyst for the anode, the overpotential required for oxygen evolution reaction (OER) can be increased. During the production of $\mathrm{O}_{3}$, the increased overpotential required for OER results in partial inhibition of the oxygen evolution when compared to a material with a lower overpotential for OER $[10,11]$. Extensive research on catalyst suitability has been studied with varying degrees of success. Among the most common catalysts used are $\beta-\mathrm{PbO}_{2}$ [10-12], Pt [13], dimensionally stable anodes (DSAs) [14], boron-doped diamond [15, 16] and $\mathrm{SnO}_{2}$ based 
catalysts [17-19]. Foller et al., one of the pioneering groups in the study of electrochemical $\mathrm{O}_{3}$ formation, used $\beta-\mathrm{PbO}_{2}$ as the catalyst of choice. Using new and innovative methods $\mathrm{O}_{3}$ was produced electrochemically. Foller summarised his research into four points:

- The anion must be resistant to further oxidation, or oxidize into a species that doesn't decrease the yield

- The cation must undergo no cathodic reduction, nor be influenced by $\mathrm{pH}$ change

- Salt combinations must have sufficient solubility

- No reactions with the ozone produced must occur

Previous methods produced $\mathrm{O}_{3}$ in low yield, resulting in low CEs. $\beta-\mathrm{PbO}_{2}$ was the first to achieve a better CE than the CCD method, with values as high as $13 \%$ at room temperature [10]. Higher efficiencies were possible with the addition of a fluorinated anion; yielding CEs as high as $50 \%$, although this occurred at $0{ }^{\circ} \mathrm{C}$. As the goal is to produce highly efficient anodes whilst being as green as possible, the use of fluorine or other halogens are disapproved.

Although in these studies a significant amount of understanding has been gained there are still questions that need to be answered:

- Is the mechanism postulated correct or will it proceed via an alternative pathway?

- Are there any surface oxidants present?

- What role do these oxidants/adsorbents play?

The focus of this research is to address these questions within the parameters that can be studied using theoretical methods, with the aim to gain a reasonable yet computationally affordable approach to understanding the electrochemical $\mathrm{O}_{3}$ production system, which has proven difficult to achieve in the past, and thus difficult to model. With this work being novel as a first theoretical study, simulations had to be run in order to determine the most stable facet of the $\mathrm{PbO}_{2}$ anode, along with the optimal surface oxygen coverage. From this a phase diagram can be constructed which aids in determining surface oxidant coverage, which in turn is important for modelling the reaction.

The main purpose of this research involved the modelling of a 4 step mechanism where water can be split to form $\mathrm{O}_{3}$ under the suitable electrochemical conditions. The modelling was carried out using Density Functional Theory (DFT). $\beta-\mathrm{PbO}_{2}$, the experimentally approved 
catalyst of choice for this reaction, was chosen. It is a relatively simple system where the results gained could then be applied to more complex catalysts.

\section{Theoretical Methods}

\subsection{Surface Adsorption Calculations}

The adsorption energy $\left(\mathrm{E}_{\mathrm{ads}}\right)$ was calculated using the following equation:

$$
\begin{gathered}
\mathrm{E}_{\text {ads }}(\text { adsorbate })=\mathrm{E}(\text { adsorbate on surf. })-\mathrm{E}(\text { surf. })-\mathrm{E}(\text { free adsorbate in the } \\
\text { gas phase })
\end{gathered}
$$

Equation 3 shows that the more negative the adsorption energy is, the greater the adsorption to the surface. In this instance it can be a clean surface or an oxide surface, depending upon the study. Each term in the equation must correspond to the same surface coverage, whether this is a pure metal or metal oxide.

Geometric optimization was obtained by performing electronic structure calculations using the Vienna Ab-initio Simulation Package (VASP), using plane wave basis set [20-22]. Electron exchange and correlation terms were described using the Perdew-Burke-Ernzerhof (PBE) functional [23]. Electron-ion interactions were modelled using the projected augmented wave (PAW) potential with system converging with cut-off energy of $500 \mathrm{eV}$ [24].

The ground state was determined using Methfessel-Paxton smearing of $0.05 \mathrm{eV}$ [25]. The most stable $\beta-\mathrm{PbO}_{2}$ system was a (110) surface. This was modelled as a (2x2) unit cell on surface coverage's barring the $0.125 \mathrm{ML}(\mathrm{ML}=$ mono-layer $)$ coverage. This coverage employed the use of a super cell modelled as a $(4 \times 2)$ unit cell. The k-points for the surfaces with $(2 \times 2)$ unit cell were sampled using a 3x3x1 Monkhorst-Pack grid [26] with the super cell having k-points $1 \times 3 \times 1$. A four-layered slab was employed, with the bottom two layers fixed in geometry, whereas top two layers were allowed to relax. Slab separation was provided normal to the surface by use of a $15 \AA$ vacuum region. Transition state (TS) searching was implemented using a constrained minimisation method [27-29].

\section{Results and Discussion}




\subsection{Determination of the most stable facet of $\mathrm{PbO}_{2}$}

$\mathrm{PbO}_{2}$ can exist in two crystalline forms; the alpha version which is orthorhombic and the beta version which is tetragonal in shape. It has been suggested that the beta version is the more favoured structure for $\mathrm{O}_{3}$ evolution. The alpha form is said to have better contact between particles, due to its more compact structure in comparison with the beta form. This compactness results in difficulty with discharge. For these reasons the beta form is often used when carrying out $\mathrm{O}_{3}$ evolution [30] .

Although studies on other surfaces were carried out, Foller and Tobias focused on exploring $\beta-\mathrm{PbO}_{2}$ as their catalyst of choice for $\mathrm{O}_{3}$ evolution. Other groups have also studied this system experimentally; however there are no examples in the literature studied on a theoretical level. Before modelling the reaction, the most stable surface facet had to be calculated. As this work is the first theoretical attempt, data on surface stability or morphology was lacking, so some common surface geometries were tested. The surface of $\beta$ $\mathrm{PbO}_{2}$ is analogous to $\mathrm{SnO}_{2}$, which has been studied previously. The (110) facet is reported as the most stable for $\mathrm{SnO}_{2}$, so this was chosen as a sensible starting point. The four arrangements tested were (110), (111), (100) and (211) mono-atomic step edge facets.

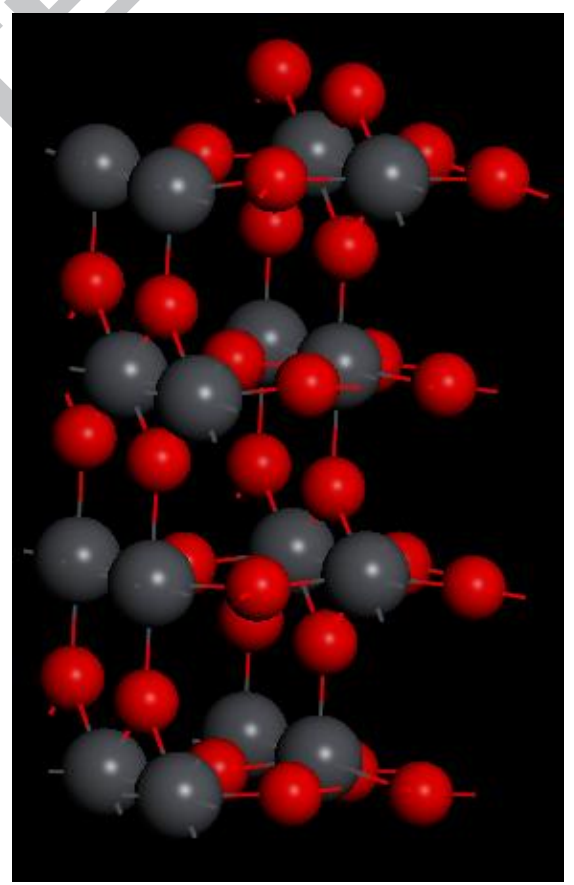

Figure 1. A diagram showing $\beta-\mathrm{PbO}_{2}$ (110), the most stable surface facet, modelled as a four layer system. The grey atoms represent lead, and the red atoms represent oxygen. 
Upon calculation of these different facets, the most stable one was found to be the (110) facet (Figure 1) and therefore this is the surface that the mechanism was modelled upon.

\subsection{Surface oxidants}

After calculating a stable facet, formation of surface oxidants from water adsorption and activation can be calculated which in turn can be useful in constructing a phase diagram (Figure 2). $\beta-\mathrm{PbO}_{2}$ (110) has four lead sites on its surface, two on the top site region and two on the bridging region. It is therefore possible to have $0.25,0.50,0.75$ and $1 \mathrm{ML}$ surface oxidant coverage.

The main surface oxidants expected are either $\mathrm{O}$ or $\mathrm{OH}$ or both at the same time. As this is oxidation reaction, it is loss of electrons and therefore a proton is released in step 1 of the mechanism. Although unlikely, there is the possibility of surface $\mathrm{H}^{+}$and this must also be taken into account.

\subsubsection{Construction of a phase diagram showing surface oxidant formation}

Each calculation will yield an energy value; this is the total energy of the system. When constructing a phase diagram, it is the free energy that is required. The free energy change $(\Delta \mathbf{G})$ of the system can be calculated using equation 4 :

$$
\Delta \mathbf{G}=\Delta \mathbf{E}+\mathbf{Z P E}-\mathbf{T} \Delta \mathrm{S}
$$

$\Delta \mathrm{E}$ is the total energy change, ZPE is zero-point energy and the $\mathrm{T} \Delta \mathrm{S}$ is the temperature and the change of the entropy of the system. The free energy change of the system accounts for the zero-point energy and the entropy associated. Temperature is also factored into this, along with a $\mathrm{pH}$ correction factor, as experimentally the reaction is carried out in acidic electrolyte. 


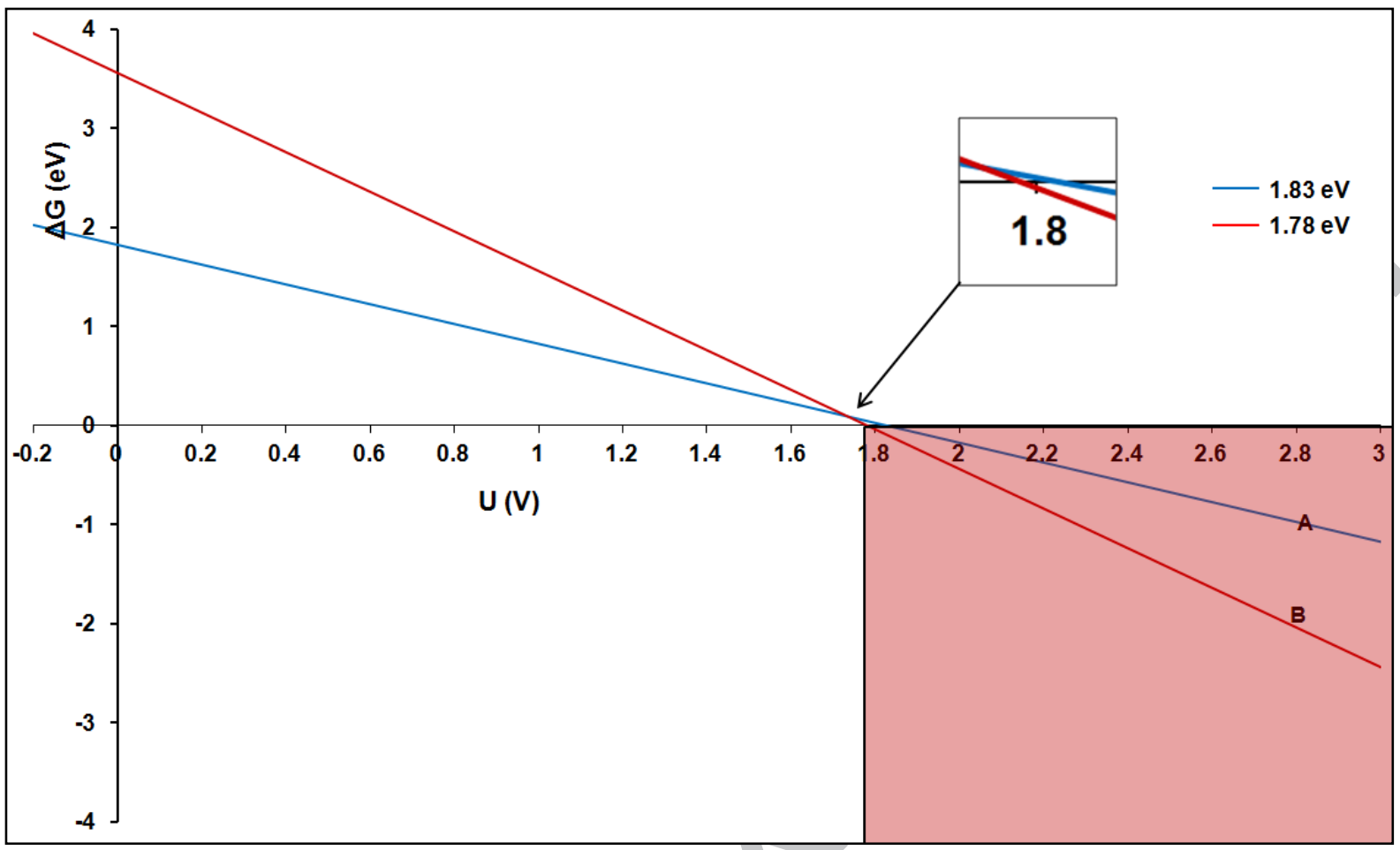

Figure 2. Plot of $\Delta G$ of formation of surface oxidants against applied potential (vs. SHE) on the $\mathrm{\beta}-\mathrm{PbO}_{2}$ surface. The blue line (line A) represents the stability of adsorbed $\mathrm{OH}$ with potential and the red line (line $B$ ) represents the stability of adsorbed $O$ with potential. The white area $(\Delta G>0)$ represents the potential region where no surface oxidants are present and the red area $(\Delta G<0)$ represents the potential region in which $O$ is the predominant surface oxidant.

\subsection{A comparison of the formation of $\mathrm{O}_{3}$ via two different pathways}

The mechanism being modelled has four steps that involve the splitting of $\mathrm{H}_{2} \mathrm{O}$ to $\mathrm{O}_{2}$ (ads) intermediate before forming $\mathrm{O}_{3}$ through the interaction with further surface $\mathrm{O}$. This is better illustrated in reactions 5-8:

$$
\begin{gathered}
\mathrm{H}_{2} \mathrm{O} \longrightarrow \mathrm{OH}_{(\mathrm{ads})}+\mathrm{H}^{+}+\mathrm{e}^{-} \\
\mathrm{OH}_{(\mathrm{ads})} \longrightarrow \mathrm{O}_{(\mathrm{ads})}+\mathrm{H}^{+}+\mathrm{e}^{-} \\
2 \mathrm{O}_{(\mathrm{ads})} \longrightarrow \mathrm{O}_{2(\mathrm{ads})} \longrightarrow \mathrm{O}_{2} \\
\mathrm{O}_{2(\mathrm{ads})}+\mathrm{O}_{(\mathrm{ads})} \longrightarrow \mathrm{O}_{3(\mathrm{ads})} \longrightarrow \mathrm{O}_{3}
\end{gathered}
$$

The first two steps (reactions 5 and 6) happen almost simultaneously as a fixed potential is applied across the anode surface. The main focus of this study is steps 3 and 4 (reactions 7 and 8). Step 3 is the formation of $\mathrm{O}_{2}$ as shown in Figures 3 and 4 , and step 4 is the formation of $\mathrm{O}_{3}$ from the $\mathrm{O}_{2}$ formed in step 3 and further surface $\mathrm{O}$, as shown in Figure 5. 


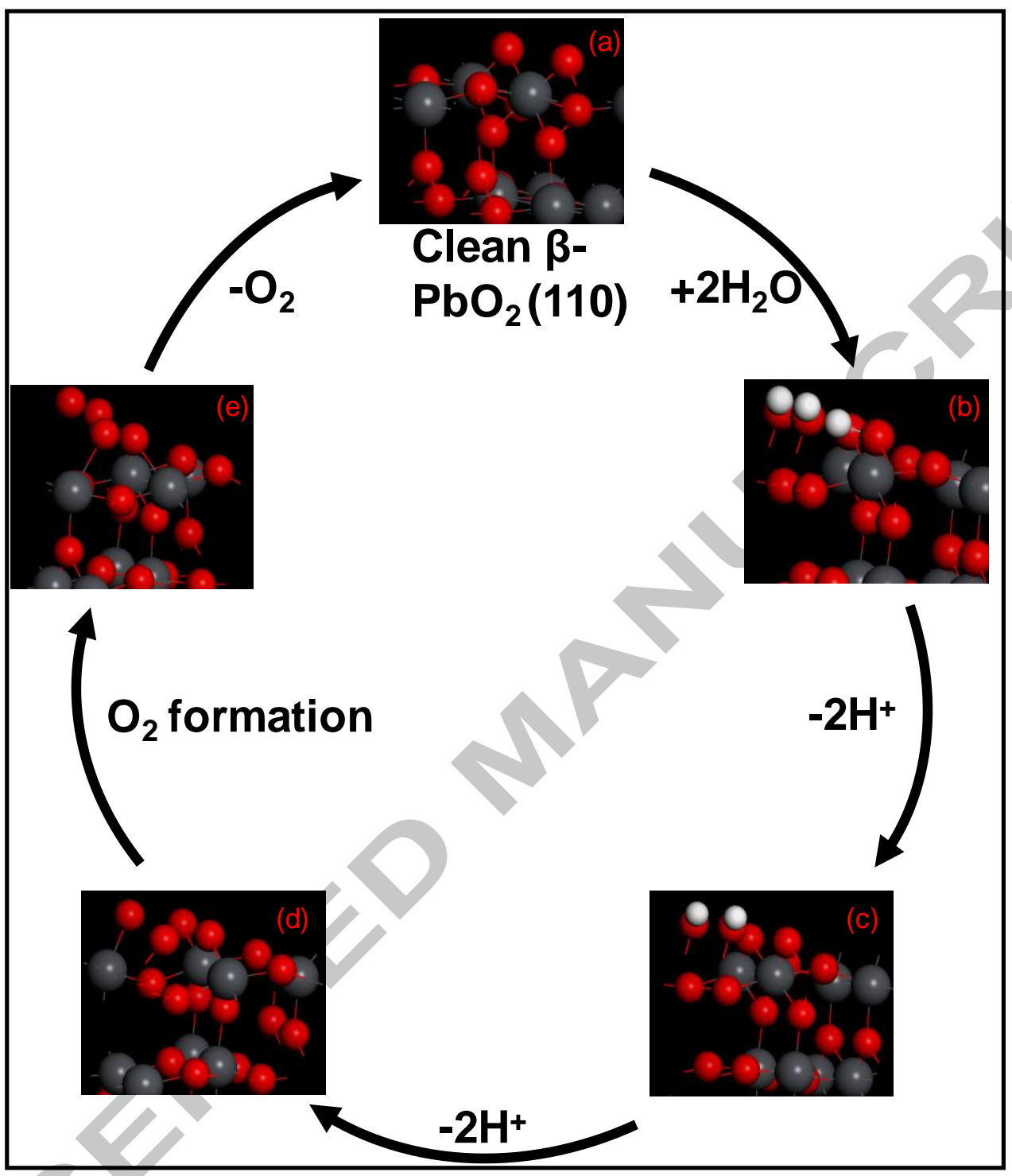

Figure 3. A flow mechanism showing steps 1 to 3 of the overall mechanism. (a) is the clean surface, (b) shows the adsorption of $\mathrm{H}_{2} \mathrm{O}$, (c) shows the deprotonation of one $\mathrm{H},(d)$ shows the deprotonation of the second $H$ and $(e)$ shows the formation and subsequent desorption of $\mathrm{O}_{2}$ back to the clean surface

\subsubsection{Step 3 - The formation of $\mathrm{O}_{2}$ via the combination of two surface $\mathrm{O}$ atoms}

In this step there are two oxygen atoms on the surface that combine to form $\mathrm{O}_{2}$.

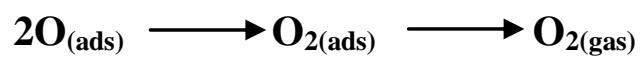


In all chemical reactions there is an initial state (IS), transition state (TS) and final state (FS). The initial state is the starting point, the transition state is when the surface adsorbates are highest in potential energy and the final state is one in which the desired reaction has reached completion. In this case the IS was the adsorbed $\mathrm{O}$ along with bridging $\mathrm{O}$, and the FS will be surface adsorbed $\mathrm{O}_{2}$. Upon completion of the calculations a reaction profile can be constructed:

\section{Initial state of reaction}

The initial mechanistic step involves two bridging oxygen atoms on the original surface and 0.50 ML coverage of oxygen present on the top site region. The bond distance between topsite and bridging is $2.199 \AA$. The energy associated with its stable configuration was calculated to be $-258.95 \mathrm{eV}$.

\section{Transition state}

The TS was identified as the point that is highest in energy. In this case it can be described as the point in which the two adjacent $\mathrm{O}$ atoms are closest without bond formation taking place. By using computational methods a suitable TS can be identified. After calculating an adsorbates most stable geometry, i.e., a geometry optimization, a frequency calculation can be run. The outcome of these calculations should result in a number of determined frequency values, depending on the level of surface coverage. Of these frequency values, at least one should be an imaginary frequency (f/i). If all frequencies calculated are real then the configuration tested is, in fact, not a TS and so adjustments need to be made, the most common of which is to configure the bond distances. 


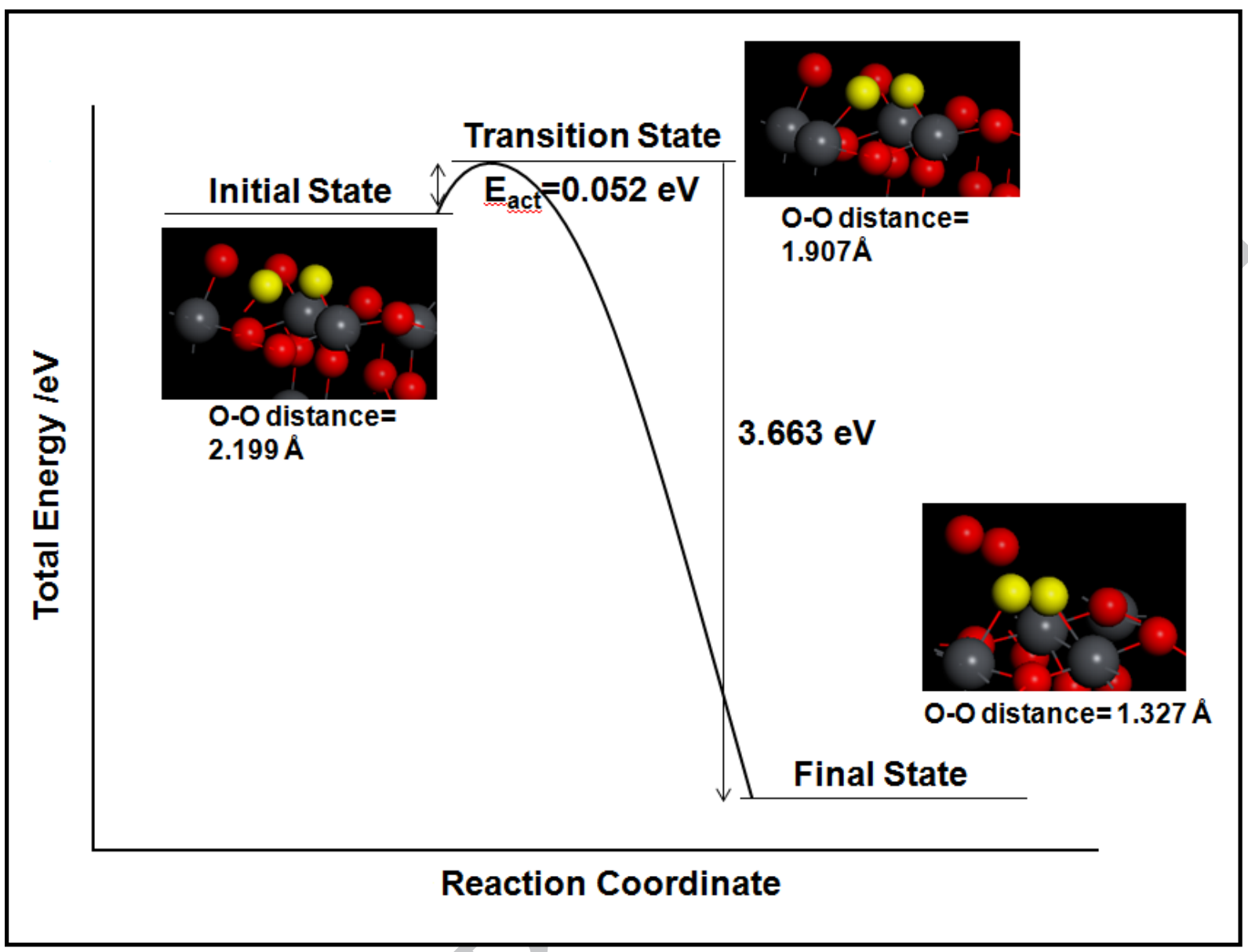

Figure 4. Energy profile for step 3 of the mechanism: the formation of surface $\mathrm{O}_{2}$ from two adsorbed oxygen atoms. The atoms highlighted in yellow are the interacting $O$ atoms in the mechanism. The initial state shows the adsorbed $O$ and bridging surface $O$, the transition state shows both these atoms in a closer proximity to one another, and the final state shows both atoms bonded to form surface $\mathrm{O}_{2}$.

The progression from IS to TS will have an activation energy $\left(\mathrm{E}_{\mathrm{act}}\right)$ associated with it. This barrier can be determined by taking IS away from the TS:

$$
\mathbf{E}_{\text {act }}=\mathrm{E}_{\mathrm{TS}}-\mathrm{E}_{\mathrm{IS}}=(-258.90)-(-258.95)=0.05 \mathrm{eV}
$$

For step 3 the activation barrier was calculated at only $0.05 \mathrm{eV}$. Thermodynamically the progression from IS to TS will occur with ease. Both the TS and IS have similar properties and so there is little change structurally, barring the bond lengths between the two states (Figure 4). 


\section{Final state of reaction}

The FS of step 3 shows the formation of surface adsorbed $\mathrm{O}_{2}$. This occurs via the reaction of the same top site-bridging oxygen interaction seen in the IS. The resulting structure shows the successful formation of $\mathrm{O}_{2}$, with the non-interacting oxygen atoms forming $\mathrm{O}_{2}$ on the surface. As a result little $\mathrm{O}_{2}$ remains adsorbed whereas the majority will desorb. This is what is expected to happen as for $\beta-\mathrm{PbO}_{2}, \mathrm{CE}$ values struggle to reach $10 \%$. This suggests that for every one hundred $\mathrm{O}_{2}$ formed only ten will remain adsorbed.

The enthalpy change $(\Delta \mathrm{H})$ associated with the overall reaction from the IS to the FS was calculated in equation 11:

$$
\Delta \mathbf{H}=\mathrm{E}_{\mathrm{FS}}-\mathrm{E}_{\mathrm{IS}}=(-262.61)-(-258.95)=-3.66 \mathrm{eV}
$$

A value of $-3.66 \mathrm{eV}$ would suggest that the FS is more stable than the IS and thus the reaction from IS to FS is exothermic.

After formation of surface $\mathrm{O}_{2}$ the adsorption energy can be calculated to determine the strength of adsorption (equation 12).

$$
\begin{aligned}
\mathbf{E}_{\text {ads }}\left(\mathbf{O}_{2}\right) & =\mathrm{E}\left(\text { surface } \mathrm{O}_{2}\right)-\mathrm{E}(\text { clean surface })-\mathrm{E}\left(\mathrm{O}_{2}\right) \\
& =(-252.69)-(-242.77)-(-9.85)=-0.11 \mathrm{eV}
\end{aligned}
$$

The adsorption energy for $\mathrm{O}_{2}$ was calculated at $-0.11 \mathrm{eV}$. This shows a weak adsorption of $\mathrm{O}_{2}$ to the surface. Although modelling was carried out in the gas phase, experimentally an acidic electrolyte was used, so is in actual fact a liquid phase reaction. Bearing this in mind it is assumed the aqueous electrolyte will have a stabilisation effect of around $-0.30 \mathrm{eV}$ associated with it $[31,32]$. If the reaction had therefore been modelled as liquid phase then the adsorption energy would be around $-0.40 \mathrm{eV}$ therefore significantly increasing its stability. To further explain this stabilization effect, imagine that the $\mathrm{H}_{2} \mathrm{O} /$ electrolyte solution is acting as a cage of hydrogen bonding over the surface. If the $\mathrm{O}_{2}$ is continually desorbing, this will disrupt the hydrogen bonding network associated with the liquid phase and so $\mathrm{O}_{2}$ will be more likely to stay adsorbed to the surface with less $\mathrm{O}_{2}$ rupturing through this network. 


\subsubsection{Step 4- The association of surface $\mathrm{O}_{2}$ and $\mathrm{O}^{\bullet}$ to form $\mathrm{O}_{3}$}

Step 4 of the reaction is the interaction of surface $\mathrm{O}_{2}$ and surface $\mathrm{O}$. This step is the most challenging of the 4 steps. The formation of $\mathrm{O}_{2}$ is thermodynamically favoured over $\mathrm{O}_{3}$ formation. Experimentally, a high potential is required to drive the reaction towards the formation of $\mathrm{O}_{3}$. Initial calculations proved unsuccessful. Although $\mathrm{O}_{3}$ was formed the activation barrier was found to be $1.56 \mathrm{eV}$. MD (molecular dynamic) calculations in the presence of $\mathrm{H}_{2} \mathrm{O}$ were carried out to try to further assess the activation barrier. These calculations are time consuming and a minimum of 10,000 iterations are needed to reach converge. Calculations in this case yielded little success and thus were not investigated further.

Rather than forming $\mathrm{O}_{3}$ via an $\mathrm{OH}$ intermediate, the $\mathrm{OH}$ was deprotonated prior to the interaction with surface $\mathrm{O}_{2}$ forming $\mathrm{O}_{3}$. Step 4, unlike step 3 was carried out in the presence of four $\mathrm{H}_{2} \mathrm{O}$ molecules positioned above the $\beta-\mathrm{PbO}_{2}$ surface. Instead of running more $\mathrm{MD}$ calculations, the basic principles were adopted and geometry optimization calculations determined instead.

$I^{\text {st }}$ step: The adsorption of $\mathrm{H}_{2} \mathrm{O}$

Further surface $\mathrm{O}$, which could be achieved by adsorption of $\mathrm{H}_{2} \mathrm{O}$ onto the surface at either the free top or bridging site (see below), is still required for step 4 (Reaction 13).

$$
\mathrm{O}_{2}+\mathrm{O}^{\circ} \longrightarrow \mathrm{O}_{3}
$$

The adsorption energy of $\mathrm{H}_{2} \mathrm{O}$ can be calculated using equation 14 :

$$
\begin{aligned}
\mathbf{E}_{\text {ads }}\left(\mathbf{H}_{2} \mathbf{O}\right) & =\mathrm{E}\left(\text { surface }-\mathrm{H}_{2} \mathrm{O}\right)-\mathrm{E}(\text { clean surface })-\mathrm{E}\left(\mathrm{H}_{2} \mathrm{O}\right) \\
& =(-326.49)-(-311.69)-(-14.22)=-0.59 \mathrm{eV}
\end{aligned}
$$

The bridging water was found to be more stable than its top-site counterpart. The adsorption energy was calculated at $-0.59 \mathrm{eV}$, suggesting that adsorption was viable and could continue to the deprotonation step. 
$2^{\text {nd }}$ step- The deprotonation to $\mathrm{OH}$ and subsequently to $\mathrm{O}$

Upon adsorption of $\mathrm{H}_{2} \mathrm{O}$, a subsequent deprotonation to $\mathrm{OH}$, followed by a second deprotonation to $\mathrm{O}$ takes place. The Gibbs free energy change of reaction $\left(\Delta \mathrm{G}_{\mathrm{rxn}}\right)$ for each of the deprotonations was calculated using equation 15 :

$$
\begin{aligned}
\Delta G_{\text {rxn }}^{0} & =G(O H)+G\left(H^{+}+e^{-}\right)-G\left(H_{2} O\right) \\
& =(-321.29)+(-3.44)-(-325.90)=1.17 \mathrm{eV}
\end{aligned}
$$

The $\Delta \mathrm{G}_{\text {rxn }}^{0}$ requires free energy which can be obtained by calculating the frequency. The $\Delta \mathrm{G}^{0}{ }_{\mathrm{rxn}}$ for this deprotonation is calculated at $1.17 \mathrm{eV}$. This value can be used to determine the minimum potential of $1.17 \mathrm{~V}$ required for this deprotonation to occur [33], which is in agreement with an experimental onset potential of $1.80 \mathrm{~V}$ or above [9].

A second deprotonation will simultaneously occur after the first and so the minimum potential is again calculated using equation 15:

$$
=(-316.20)+(-3.44)-(-321.29)=1.65 \mathrm{eV}
$$

The $\Delta \mathrm{G}_{\mathrm{rxn}}^{0}$ for this deprotonation is calculated at $1.65 \mathrm{eV}$. Again this value corresponds to the minimum potential of $1.65 \mathrm{~V}$ required for deprotonation to surface O.As aforementioned this is below the experimental onset $1.80 \mathrm{~V}$ and so will readily take place.

$3^{\text {rd }}$ step- The reaction of $\mathrm{O}_{2}$ and $\mathrm{O}$ to form surface $\mathrm{O}_{3}$

At this point there are both surface $\mathrm{O}_{2}$ and $\mathrm{O}$ present. Like step 3, there will be an IS, TS and FS associated with the step. The IS was surface $\mathrm{O}_{2}$ and $\mathrm{O}$, the TS shows $\mathrm{O}_{2}$ and $\mathrm{O}$ in close proximity to one another without any bonding and the FS corresponds to surface adsorbed $\mathrm{O}_{3}$.

\section{Initial state of reaction}

In this step the bond distance between $\mathrm{O}_{2}$ and $\mathrm{O}$ was $3.34 \AA$. Upon completion stable geometric configuration was determined with a total energy of $-316.22 \mathrm{eV}$.

\section{Transition state}


In this step the bond distance shortened from $3.34 \AA$ in the IS to $1.77 \AA$ in the TS. The energy associated with the TS is $-315.81 \mathrm{eV}$. A frequency calculation was performed to determine if there is an imaginary frequency ( $\mathrm{f} / \mathrm{i}$ ). There is one $\mathrm{f} / \mathrm{i}$, suggesting the TS is suitable.

The energy barrier $\left(\mathrm{E}_{\mathrm{act}}\right.$ ) from IS to TS was determined by Equation 16:

$$
\begin{aligned}
& \mathbf{E}_{\mathbf{a c t}}=\mathrm{E}_{\mathrm{TS}}-\mathrm{E}_{\mathrm{IS}} \\
& \mathbf{E}_{\mathbf{a c t}}=(-315.81)-(-316.22)=0.41 \mathrm{eV}
\end{aligned}
$$

The barrier of $0.41 \mathrm{eV}$ can be bypassed with relative ease. Considering the value for $\mathrm{O}_{2}$ adsorption calculated earlier (equation 12), one would assume that this large difference in energy would prevent the reaction with surface $\mathrm{O}$ shown in step 4 . When you take into account the water stabilization effect discussed previously, the adsorption of $\mathrm{O}_{2}$ becomes more substantial $(\sim 0.40 \mathrm{eV})$, thus increasing the time for surface $\mathrm{O}_{2}$ to react with surface $\mathrm{O}$ before desorption. The $\mathrm{CE}$ for this system is low, thus only a small portion of $\mathrm{O}_{2}$ will stay adsorbed long enough to react and form $\mathrm{O}_{3}$.

In a comparison of $\mathrm{O}_{3} \mathrm{H}$ vs $\mathrm{O}_{3}$, the $\mathrm{O}_{3}$ pathway is heavily favoured. At $1.56 \mathrm{eV}$, the $\mathrm{O}_{3} \mathrm{H}$ barrier is $1.15 \mathrm{eV}$ higher than for $\mathrm{O}$, which in itself is a massive reduction. This shows the importance of choosing a suitable intermediate; and by deprotonating first before forming $\mathrm{O}_{3}$ is much more favourable. The major difference is that the reaction of $\mathrm{O}_{2}+\mathrm{O}$ was carried out in the presence of $4 \mathrm{H}_{2} \mathrm{O}$, whereas the $\mathrm{O}_{3} \mathrm{H}$ pathway was not. To make this a viable study, the $\mathrm{O}_{3} \mathrm{H}$ pathway was run in the presence of $4 \mathrm{H}_{2} \mathrm{O}$ and the barrier was lowered to $1.17 \mathrm{eV}$. This was still much too high and so for this particular catalyst, the $\mathrm{O}_{2}+\mathrm{O}$ pathway (having a barrier of $0.41 \mathrm{eV}$ ) will always be favoured.

\section{Final state of reaction}

The final state is the formation of $\mathrm{O}_{3}$ from $\mathrm{O}_{2}$ and $\mathrm{O}$. The enthalpy change from IS to FS was calculated using equation 17 :

$$
\begin{aligned}
& \Delta \mathbf{H}=\mathrm{E}_{\mathrm{FS}}-\mathrm{E}_{\mathrm{IS}} \\
& =(-316.29)-(-316.22)=-0.07 \mathrm{eV}
\end{aligned}
$$


The enthalpy change from IS to FS is $-0.07 \mathrm{eV}$, suggesting the FS is therefore slightly more stable than the IS in this exothermic reaction (Figure 5).

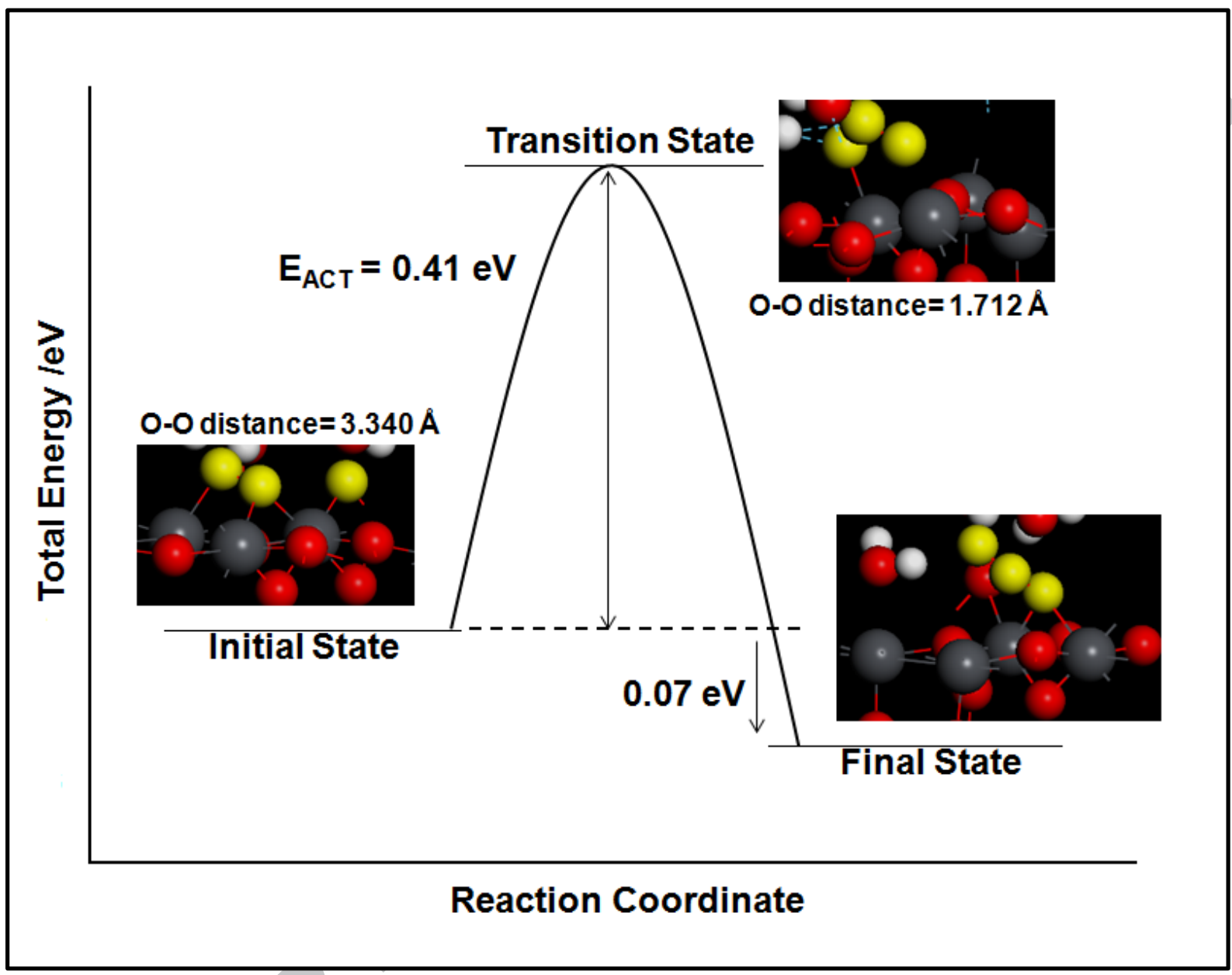

Figure 5. Energy profile for step 4 of the mechanism: the transformation from $\mathrm{O}_{2}$ and $\mathrm{O}$ to $\mathrm{O}_{3}$. The atoms highlighted in yellow are the interacting $O$ atoms in the mechanism. The first shows surface $\mathrm{O}_{2}$ and $\mathrm{O}$, the second shows the $\mathrm{O}_{2}$ desorbed with $\mathrm{O}$ still adsorbed, and the third shows $\mathrm{O}_{3}$ adsorbed on the surface

\section{Conclusions}

This work represents a first theoretical attempt at gaining an insight into $\mathrm{O}_{3}$ production from water splitting via electrochemistry. Using Density Functional Theory calculations we were able to model possible ozone formation pathways and verify a favourable mechanism. By taking a $\beta-\mathrm{PbO}_{2}$ (110) surface as a model catalyst, we have identified a feasible path where $\mathrm{H}_{2} \mathrm{O}$ adsorbed onto the surface and was oxidized to form surface $\mathrm{OH}$ then $\mathrm{O}$, the latter 
reacted with a surface bridging $\mathrm{O}$ to form $\mathrm{O}_{2}$ which in turn reacted with further surface $\mathrm{O}$ to form $\mathrm{O}_{3}$.

\section{Acknowledgments}

We thank the Department of Education and Learning (DEL) of Northern Ireland, and Loughborough University, for the support of this project.

\section{References}

[1] U.E.P. Agency, Office of Water, (1999) 4607.

[2] C. Zwiener, F.H. Frimmel, Oxidative treatment of pharmaceuticals in water, Water Research, 34 (2000) 1881-1885.

[3] R.J. Bull, L.S. Birnbaum, K.P. Cantor, J.B. Rose, B.E. Butterworth, R. Pegram, J. Tuomisto, Water Chlorination: Essential Process or Cancer Hazard?, Fundamental and Applied Toxicology, 28 (1995) 155-166.

[4] F. L, The Application of Ozone Technology for Public Health and Industry, White Paper, (2005).

[5] M.X. Meng, J.S. Hsieh, J. Tappi, 83 (2000) 6772.

[6] D. Iliadis, B.J. Millar, Ozone and its use in periodontal treatment, Open Journal of Stomatology, 3 (2013) 197-202.

[7] J. Lee, B. Jeong, J.D. Ocon, Oxygen electrocatalysis in chemical energy conversion and storage technologies, Current Applied Physics, 13 (2013) 309-321.

[8] J. Wang, Electrochemical Glucose Biosensors, Chemical Reviews, 108 (2008) 814-825.

[9] P.A. Christensen, W.F. Lin, H. Christensen, A. Imkum, J.M. Jin, G. Li, C.M. Dyson, Room Temperature, Electrochemical Generation of Ozone with 50\% Current Efficiency in 0.5M Sulfuric Acid at Cell Voltages <3V, Ozone: Science \& Engineering, 31 (2009) 287293.

[10] P.C. Foller, C.W. Tobias, The Anodic Evolution of Ozone, Journal of The Electrochemical Society, 129 (1982) 506-515.

[11] L.M. Da Silva, L.A. De Faria, J.F.C. Boodts, Electrochemical ozone production: influence of the supporting electrolyte on kinetics and current efficiency, Electrochimica Acta, 48 (2003) 699-709. 
[12] R. Amadelli, L. Armelao, A.B. Velichenko, N.V. Nikolenko, D.V. Girenko, S.V. Kovalyov, F.I. Danilov, Oxygen and ozone evolution at fluoride modified lead dioxide electrodes, Electrochimica Acta, 45 (1999) 713-720.

[13] I. Awad M, M. Saleh M, T. Ohsaka, Journal of Electrochemical Society, 153 (2006) D207-D212.

[14] L.M. Da Silva, D.V. Franco, L.A. De Faria, J.F.C. Boodts, Surface, kinetics and electrocatalytic properties of $\mathrm{Ti} /\left(\mathrm{IrO}_{2}+\mathrm{Ta}_{2} \mathrm{O}_{5}\right)$ electrodes, prepared using controlled cooling rate, for ozone production, Electrochimica Acta, 49 (2004) 3977-3988.

[15] A. Kraft, M. Stadelmann, M. Wünsche, M. Blaschke, Electrochemical ozone production using diamond anodes and a solid polymer electrolyte, Electrochemistry Communications, 8 (2006) 883-886.

[16] K. Arihara, C. Terashima, A. Fujishima, Electrochemical and Solid-State Letters, 9 (2006) D17-D20.

[17] Y. Wang, H., S. Cheng, K.-Y. Chan, X.Y. Li, Electrolytic Generation of Ozone on Antimony- and Nickel-

Doped Tin Oxide Electrode, Journal of Electrochemical Society, 152 (2005) D197-D200.

[18] H. Shekarchizade, M.K. Amini, International Journal of Electrochemistry, (2011) 1-13.

[19] S. Cheng, K.-Y. Chan, Electrochemical and Solid-State Letters, 7 (2007) D4-D6.

[20] G. Kresse, J. Hafner, Ab initio molecular dynamics for liquid metals, Physical Review B, 47 (1993) 558-561.

[21] G. Kresse, J. Hafner, Ab initio molecular dynamics for open-shell transition metals, Physical Review B, 48 (1993) 13115-13118.

[22] G. Kresse, J. Hafner, Ab initio molecular-dynamics simulation of the liquid-metalamorphous-semiconductor transition in germanium, Physical Review B, 49 (1994) 1425114269.

[23] P.E. Blöchl, Projector augmented-wave method, Physical Review B, 50 (1994) 1795317979.

[24] J.P. Perdew, K. Burke, M. Ernzerhof, Generalized Gradient Approximation Made Simple, Physical Review Letters, 77 (1996) 3865-3868.

[25] M. Methfessel, A.T. Paxton, High-precision sampling for Brillouin-zone integration in metals, Physical Review B, 40 (1989) 3616-3621.

[26] H.J. Monkhorst, J.D. Pack, Special points for Brillouin-zone integrations, Physical Review B, 13 (1976) 5188-5192. 
[27] A. Alavia, P. Hu, T. Deutsch, P.L. Sylvestrelli, J. Hutter, Journal of Physical Review Letters, 80 (1998) 3650-3653.

[28] A. Michaelides, P. Hu, Insight into Microscopic Reaction Pathways in Heterogeneous Catalysis, Journal of the American Chemical Society, 122 (2000) 9866-9867.

[29] Z.-P. Liu, P. Hu, General Rules for Predicting Where a Catalytic Reaction Should Occur on Metal Surfaces: A Density Functional Theory Study of $\mathrm{C}-\mathrm{H}$ and $\mathrm{C}-\mathrm{O}$ Bond Breaking/Making on Flat, Stepped, and Kinked Metal Surfaces, Journal of the American Chemical Society, 125 (2003) 1958-1967.

[30] I. Petersson, E. Ahlberg, B. Berghult, Parameters influencing the ratio between electrochemically formed $\alpha$ - and $\beta-\mathrm{PbO}_{2}$, Journal of Power Sources, 76 (1998) 98-105.

[31] R. Kavanagh, X.-M. Cao, W.-F. Lin, C. Hardacre, P. Hu, Origin of Low $\mathrm{CO}_{2}$ Selectivity on Platinum in the Direct Ethanol Fuel Cell, Angewandte Chemie International Edition, 51 (2012) 1572-1575.

[32] T. Song, P. Hu, Insight into the solvent effect: A density functional theory study of cisplatin hydrolysis, The Journal of Chemical Physics, 125 (2006) 091101.

[33] W.-F. Lin, S.-G. Sun, Z.-Q. Tian, Z.-W. Tian, Quantum chemistry and in situ FTir spectroscopy studies on potential-dependent properties of $\mathrm{CO}$ adsorbed on Pt electrodes, Electrochimica Acta, 38 (1993) 1107-1114. 

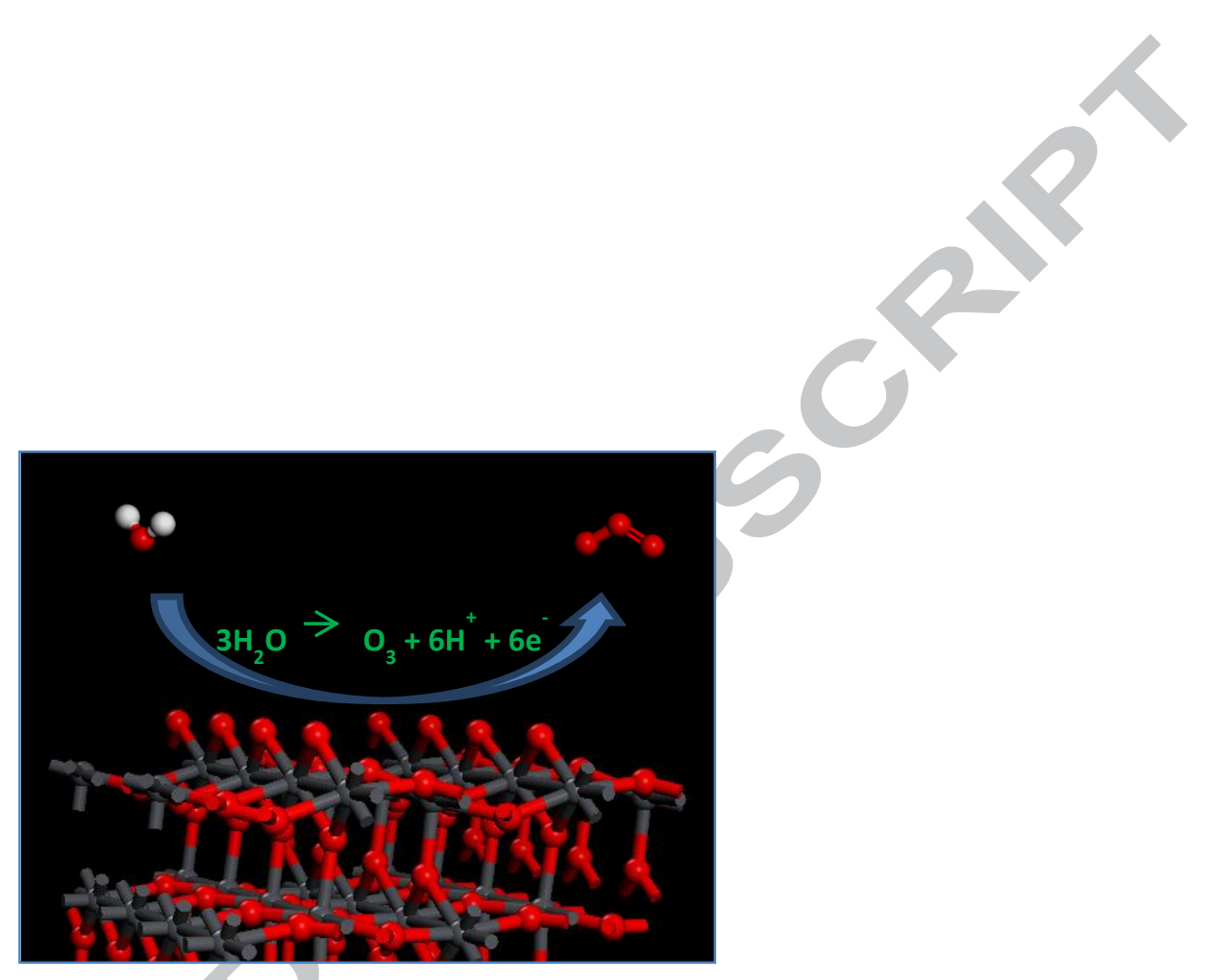


\section{Highlights}

- Mechanisms for ozone production via splitting of water identified by DFT modelling

- $\mathrm{H}_{2} \mathrm{O}$ adsorbed onto the electrode was oxidized to form surface $\mathrm{OH}$ then $\mathrm{O}$

- Eley-Rideal style interaction between $\mathrm{O}_{2}$ and surface $\mathrm{O}$ to form $\mathrm{O}_{3}$

- A different reaction pathway via an $\mathrm{O}_{3} \mathrm{H}$ intermediate was less favoured 